\title{
Impact of LCC-HVDC multiterminal on generator rotor angle stability
}

\author{
Oluwafemi E. Oni, Andrew G. Swanson, Rudiren Pillay Carpanen \\ Discipline of Electrical, Electronic and Computer Engineering, University of KwaZulu-Natal, South Africa
}

\begin{tabular}{l}
\hline \hline Article Info \\
\hline Article history: \\
Received Jan 2, 2019 \\
Revised Apr 24, 2019 \\
Accepted Jun 26, 2019 \\
\hline
\end{tabular}

\section{Keywords:}

MTDC system

Short circuit Ratio

Thyristor converters

Transient stability

Voltage dependent current

order limiter (VDCOL)

\begin{abstract}
Multiterminal High Voltage Direct Current (HVDC) transmission utilizing Line Commutated Converter (LCC-HVDC) technology is on the increase in interconnecting a remote generating station to any urban centre via long distance DC lines. This Multiterminal-HVDC (MTDC) system offers a reduced right of way benefits, reduction in transmission losses, as well as robust power controllability with enhanced stability margin. However, utilizing the MTDC system in an AC network bring about a new area of associated fault analysis as well as the effect on the entire AC system during a transient fault condition. This paper analyses the fault current contribution of an MTDC system during transient fault to the rotor angle of a synchronous generator. The results show a high rotor angle swing during a transient fault and the effectiveness of fast power system stabilizer connected to the generator automatic voltage regulator in damping the system oscillations. The MTDC link improved the system performance by providing an alternative path of power transfer and quick system recovery during transient fault thus increasing the rate at which the system oscillations were damped out. This shows great improvement compared to when power was being transmitted via $\mathrm{AC}$ lines.
\end{abstract}

Copyright (C) 2020 Institute of Advanced Engineering and Science. All rights reserved.

\section{Corresponding Author:}

Oluwafemi E. Oni,

Discipline of Electrical, Electronic and Computer Engineering,

University of KwaZulu-Natal,

238 Mazisi Kunene Rd, Glenwood, Durban 4041, South Africa.

Email: maxiphem@yahoo.com

\section{INTRODUCTION}

An increase in demand for electricity has brought Southern African power utilities into planning to expand their transmission corridor utilizing Multiterminal High Voltage Direct Current (HVDC) Transmission. This Multiterminal-HVDC (MTDC) is not only key in the integration of renewable energy such as wind farms and solar parks, but also the deployment of distributed generators into the grid. It is also important for large-scale interregional power transmission [1]. This will help bring about a smart, eco-friendly and decentralized power system. Being a region with relatively weak interconnections and high susceptibility to a transient fault, the proper analysis needs to be made to give power system planners and engineers seeking to utilize this MTDC system more understanding of the impact on generator rotor angle stability. Major setbacks of excessive usage of HVDC systems are the concern associated with the reliability and interaction with AC networks, in which the generator is a major recipient $[2,3]$. During a system fault, the generator loses a large amount of power, and this impact the entire interconnected system as well as other connected synchronous machines.

MTDC system can adopt either thyristor converter technology (LCC-HVDC) or the Insulated Bipolar Junction (IGBTs) Voltage Source Converter (VSC-HVDC) technology [4, 5]. While VSC provides $\mathrm{AC}$ networks with robustness and full controllability of $\mathrm{AC}$ active and reactive power, but the capacity of the available solid-state devices with turn-off capability are limited and still requires specially configure 
Direct Current (DC) breakers to isolate the converter during a DC line fault [6]. Unlike VSC HVDC, research studies have shown that LCC HVDC system is less susceptible to DC line fault with the use of conventional DC line protection and rugged controller [7-9]. This converter technology has the capabilities of withstanding high power and voltage ratings for bulk power transmission. Although with obstacles such as; reactive power consumption and cases of commutation failure during a fault, however, this technology still has the largest footprint with many point-to-point installations, and three MTDC link around the globe. An Example is the $1920 \mathrm{MW}, \pm 533 \mathrm{kV}$ Cahora Bassa point to point interconnection linking Mozambique and South Africa; while that of MTDC are the $8 \mathrm{GW}$ North-East Agra system (four terminals in three converter stations), $300 \mathrm{MW}, 200 \mathrm{kV}$ Sardinia-Corsica-Italy system, and the 2,000 MW, $\pm 450 \mathrm{kV}$ Hydro Québec-New England system [10-13].

Research on LCC HVDC shows that the stability level depends predominantly on the Effective Short Circuit Ratio (ESCR) of the AC grid [14-16]. The first impact is seen in the frequent occurrence of commutation failure at the inverter station during any system disturbances leading to power oscillations of the synchronous generator, which can further lead to total system collapse due to the inability of the converter station to recover from the disturbances. Power systems are often subjected to different degrees and severities of faults as a result of occurrences such as; adverse weather conditions leading to loss of transmission line, flashover discharge, or sudden loss of load, etc. There is a need for power system planners to carry out a selected set of contingencies analysis on the system for proper design and smooth-running operation of the system. The entire system is said to be transiently stable when it has the ability to maintain synchronism when subjected to a transient disturbance $[17,18]$.

The long-established method of addressing transient stability has been by using an Automatic Voltage Regulator (AVR), which helps in controlling the electromagnetic torque of the synchronous generator. The excitation system with Power System Stabilizers is also added to offer a quick response in adjusting the field current supplied during fault to match the generator capability [19, 20]. Different FACTS devices such as Static Synchronous Compensator (STATCOM), Static Var Compensator (SVC), Thyristor Controlled Series Compensator (TCSC), capacitor banks etc. were discussed in [21, 22] as other means of enhancing power system stability. Kenné et al. in [23] proposed an adaptive nonlinear excitation control for fast response and damping out of oscillations during a transient disturbance on the synchronous generator. Also, Oni and Mbangula in [2, 8, 24] observed that a point-to-point HVDC scheme gives an enhanced critical clearing time when integrated into an $\mathrm{AC}$ network, which in turn improves the generator rotor angle as well as the entire voltage profile. A report on MTDC state of the art control strategy and converter architecture was given in [25]. Jiang and Ekstrom in [26] gave an analysis of LCC MTDC systems in reducing the impact of a ground fault on sub-transmission and distribution network. They focused on the converter response of the MTDC link neglecting the synchronous generator response of the AC network. Vasquez-Arnez et al. in [27] cover both the converter response as well as the synchronous generator response in their analysis of dynamic modelling of LCC-MTDC system in an AC network, but failed to consider the AC network strength using Short Circuit Capacity (SSC) with regards to the entire network stability margin, and its effect on the interconnected synchronous machine.

In order to enhance the transient stability margin of an $\mathrm{AC}$ network, this paper gives the performance evaluation of a three-terminal HVDC model implemented on Single Machine Infinite Bus (SMIB) network, and results were obtained through simulations analysis on PSCAD. Two case studies were considered; the first scenario involved using MTDC system in parallel with AC line to interconnect the infinite bus with the synchronous generator, while the second scenario involved replacing the MTDC link with another AC line to make a double AC transmission circuit linking the synchronous generator with the infinite bus. The results of which were analysed to determine which system helped in alleviating the effect of the three-phase short circuit fault on the synchronous generator. An improvement of incorporating a voltage controller into two of the converter stations, preferably the inverters, were also implemented. The Short Circuit Ratio (SCR) of the AC network and the control setup of the DC converters to avoid reoccurring commutation failure during the modelling of the MTDC link were all taken into consideration. The fault current contribution of each converter with respect to the interconnected $\mathrm{AC}$ synchronous generator has been analysed. The power swing equation using equal area criterion was used in analysing the maximum power transfer and the fault clearing angle to allow the generator damper and protection circuit to work effectively in stabilizing the entire system.

The organization of the paper follows Section 2 analysing the short circuit ratio and short circuits level of the AC networks while Section 3 gives the generator AVR modelling and control. Section 4 gives the rotor angle stability analysis of the synchronous machine using equal area criterion. The system model and system parameters are presented in Section 5 while Section 6 gives the results and discussion. Section 7 finally presents the conclusion and contributions. 


\section{ESCR ANALYSIS}

The ESCR analysis is used in AC/DC system interaction to determine the strength of the AC network. The ratio of $\mathrm{SC}$ to the $\mathrm{DC}$ power rating (Pdc) of a converter gives the $\mathrm{SCR}$ of an $\mathrm{AC} / \mathrm{DC}$ interconnection. A weak AC system can be termed as a system with high short circuit impedance and low mechanical inertia.

In (1) - (2) from Figure 1 use the Thevenin equivalent impedance to calculate the short circuit level SCL of an ac system. When the SCL of the system is divided with rated DC power, the short circuit ratio of $\mathrm{AC} / \mathrm{DC}$ system is obtained [28]. When the reactive power generator and harmonic filters connected to the AC side of the HVDC links are considered, the ESCR of the entire AC/DC line governed by (3) is obtained. The harmonic filters behave like shunt capacitors at fundamental frequency thereby reducing the grid strength by injecting too much reactive power into the AC network during a disturbance [29]. This tends to increase the Thevenin equivalent impedance at the fundamental frequency of the AC system.

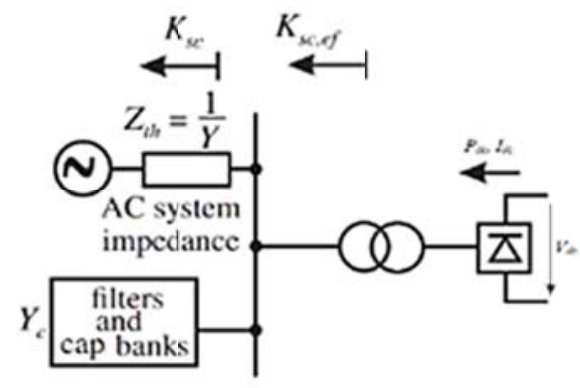

Figure 1. AC/DC system interconnection

$$
\begin{aligned}
& S C L=\frac{V_{a c}^{2}}{Z_{T h}} \\
& S C R=\frac{S C L(M W)}{P_{d c}}=\frac{V_{a c}^{2}}{P_{d c} Z_{T h}} \\
& E S C R=\frac{S C L-\left(Q_{f}+Q_{a}\right)}{P_{d c}}
\end{aligned}
$$

Where $Q_{f}$ (in MVAR) is the reactive power contribution from the harmonic filters at the fundamental frequency, and $Q_{a}$ (in MVAR) is the reactive power of any additional shunt capacitors connected to the converter station.

Using the active power (MW) rating of HVDC link, a power utility can estimate the SCR value of the networks at the initial stage of planning. The worst case of SCR has to be used in implementing the AC/DC network. AC system strength in relative to DC power transmitted is indicated in Table 1 [28].

Table 1. SCR indicator for AC/DC networks strength

\begin{tabular}{ll}
\hline SCR value & Effect on AC/DC network \\
\hline $\mathrm{SCR}>3$ & Strong grid with little or no-fault occurrence \\
$2<\mathrm{SCR}<3$ & $\begin{array}{l}\text { Intermediate grid strength, require voltage control ability like } \\
\text { functional OLTC or static VAR compensator }\end{array}$ \\
$\mathrm{SCR}<2$ & $\begin{array}{l}\text { Weak network that requires strong VAR generator, like } \\
\text { synchronous condenser or STATCOM }\end{array}$ \\
\hline
\end{tabular}

Most MTDC schemes that are currently in service are designed to operate normally at a point lower than $I_{\max }$ (maximum rated current of the converters), say at point $\left(i_{n}=1.0 p . u\right)$, due to their constant extinction angle $\gamma$ (the margin of commutation) that can be varied between $15^{\circ}$ to $18^{\circ}$. Unless changes are made to the system condition, an increasing extinction angle $(\gamma)$ can bring about an increase in active power. However, the increase must be below the maximum power curve and not above. Thus, for a given system impedance, system voltage, or any other network data of Figure 2, a definite value of SCR will bring about a unique $P_{d}-I_{d}$ characteristic which will represent the maximum power curve. 


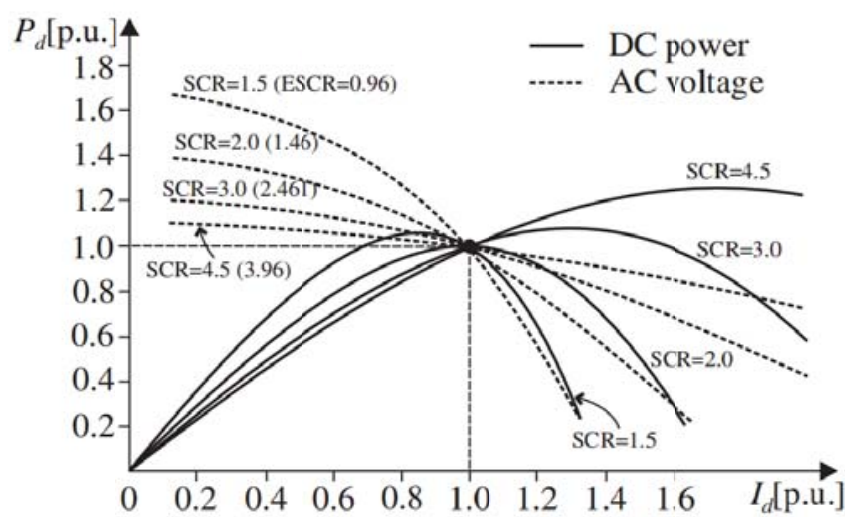

Figure 2. Active power - DC current characteristics with respect to SCR level

\section{GENERATOR MODELLING AND CONTROL}

Synchronous generator control model consists of the excitation system, Power System Stabilizer (PSS), and the generator itself. Generating plants are equipped with Automatic Voltage Regulator (AVR) in order to maintain generator stator voltage. The excitation system used in this model is the bus-fed thyristor type that includes a PSS and an AVR [30]. It also equipped with an Under-Excitation Limiter (UEL) and Over Excitation Limiter (OEL). The UEL prevents loss of synchronism when the excitation voltage falls below the reference level and the OEL helps to prevent the generator from overheating during long-term excitation overcurrent $[22,31,32]$. Figure 3 shows the PSS connected to the exciter. The shaft speed from the generator is fed into the PSS which is in turn used in damping out oscillations during power system disturbance.

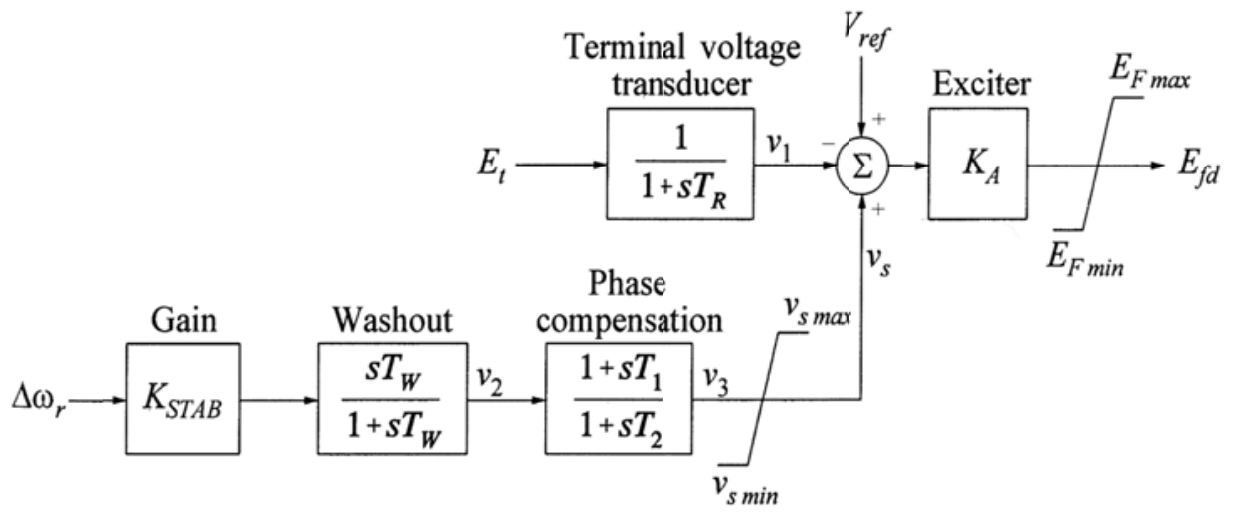

Figure 3. IEEE ST4A excitation system with AVR and PSS1A stabiliser

\section{ROTOR ANGLE STABILITY}

The Single Machine Infinite Bus (SMIB) system in Figure 4 [30], consists of a synchronous generator with a constant field voltage, linked to an infinite bus with constant frequency and voltage magnitude via two transmission line. The system equivalent equation is given in $(4,5)$, where $P_{e}$ is the terminal Power, $X_{t}$ is the total line reactance. $P_{e}$ equals $P_{\max }$ at $\delta=90^{\circ}$, corresponding to maximum power transfer during steady state. Following a three-phase to ground fault on any of the transmission lines, the power transmitted by that particular faulted line drops to zero and hence $P_{m}$ will be higher that $P_{e}$ leading to an increase rotor angle $(\delta)$. The swing equation in consideration to the inertia constant $H$ and the change in angular speed $\omega_{o}$ is given in (6). Integrating (7) gives (8), thus for a stable operation, the deviation of rotor angle $\delta$ must be bounded, i.e. the speed deviation must become zero to give the criterion for stability in (9) [30]. 


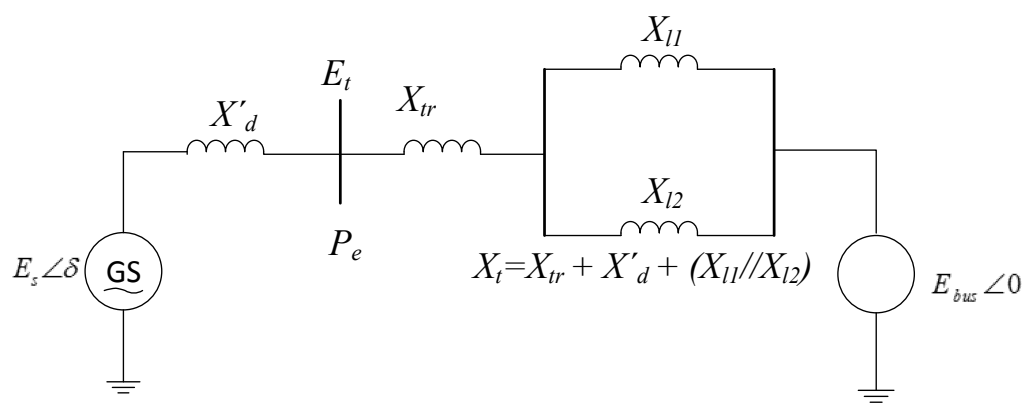

Figure 4. Equivalent SMIB network

$$
\begin{aligned}
& P_{e}=\frac{E_{G} E_{B}}{X_{t}}=P_{\max } \sin \delta \\
& P_{\max }=\frac{E_{G} E_{B}}{X_{t}} \\
& P_{m}-P_{\text {max }} \sin \delta=\frac{2 H}{\omega_{O}} \frac{d^{2} t}{d t^{2}} \\
& \left(P_{m}-P_{e}\right) \frac{\omega_{O}}{2 H}=\frac{d^{2} \delta}{d t^{2}} \\
& {\left[\frac{d \delta}{d t}\right]^{2}=\int \frac{\omega_{o}\left(P_{m}-P_{e}\right)}{H} d \delta} \\
& \int_{\delta_{o}}^{\delta_{m}} \frac{\omega_{o}}{H}\left(P_{m}-P_{e}\right) d \delta=0 \\
& \int_{\delta_{o}}^{\delta_{m}} \frac{\omega_{o}}{H}\left(P_{m}-P_{e}\right) d \delta=0 \\
& \int_{\delta_{o}}^{\delta_{1}}\left(P_{m}-P_{e}\right) d \delta-\int_{\delta_{1}}^{\delta_{m}}\left(P_{e}-P_{m}\right) d \delta \leq 0 \\
& A_{1}-A_{2} \leq 0
\end{aligned}
$$

Consider a three-phase short circuit fault of zero fault reactance being applied at line L2 of the SMIB network shown in Figure 4, and the fault is cleared by isolating the faulted line with a circuit breaker. Using the equal area criterion, a power - angle (Pe- $\delta$ ) diagram used in understanding the basics relationship between the generator accelerating power and its rotor angle according to (10), the network conditions before (2 lines in operation), during (three-phase fault on line L2), and post-fault (line L2 out of service) was evaluated. These results will give the stability limit of the system by weighing the maximum rotor angle of the system. From Figure 5, during a stable operating state, the system is bounded by area A1 (abco), a fault on the system will shift the steady-state condition from point ' $a$ ' to point ' $b$ ', causing the rotor to accelerate until operating point $\mathrm{c}$ is reached because $\mathrm{Pm}>\mathrm{Pe}$, the operating point will thus shift to point $\mathrm{b}$ after the fault has been cleared at $\delta c t 1$, causing a decelerating rotor angle. The kinetic energy gained by the rotor from area A1 is then dissipated to area A2 (odef) thus shifting further the operating point from ' $\mathrm{d}$ ' to 'e', such that $\delta$ has reached its maximum value $\delta \mathrm{m}$, and if area $\mathrm{A} 1$ is equal to area $\mathrm{A} 2$, the rotor begins to decelerate and the operating point follows the path of e to $d$ according to Pe- $\delta$ diagram. The amplitude of the oscillations reduces with the help of a damper circuit; otherwise, it continues to oscillate with a constant amplitude [33].

However, with a prolonged fault clearing time, the clearing angle will reach $\delta_{c t 2}$, the rotor angle operating point will reach point ' $\mathrm{e}$ ' leading to an unexpended kinetic energy which results in a continuous increase of the rotor speed and angle $\left(P_{e}<P_{m}\right.$ beyond 'e'). This will cause the pre-fault area $A 1\left(a b c^{\prime}{ }^{\prime}\right)$ to be greater than post-fault area $A 2$ ( $o^{\prime} d^{\prime} e$ ) (11), this eventually leads to loss of synchronism [34, 35]. 


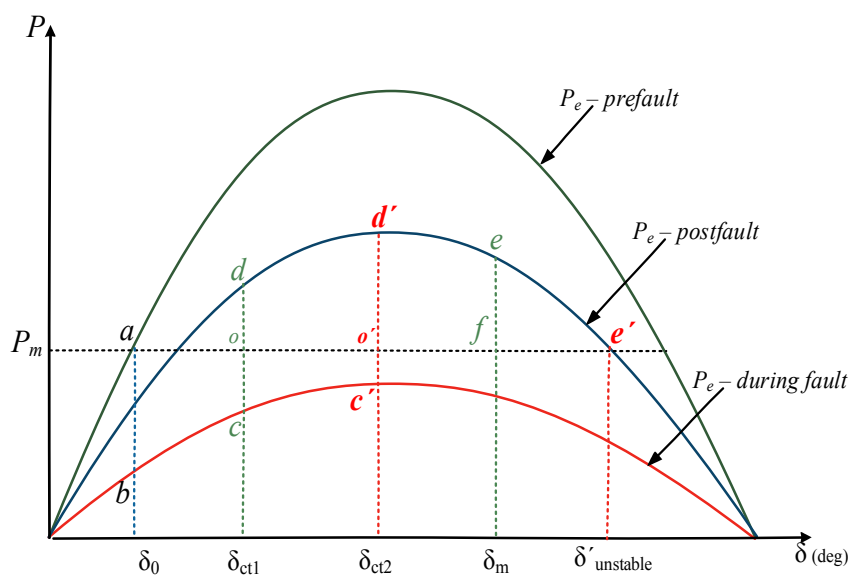

Figure 5. Pe $-\delta$ diagram for both stable and unstable system condition

A simulation result of the SMIB network during the three-phase fault at circuit 2 for $0.07 \mathrm{~s}$ is shown in Figure 6. This system recorded a slow damping of rotor angle oscillations when the generator uses a constant field supply. AVR without PSS generator control mode witnessed a second swing instability. While AVR with PSS generator control setup gives a positive fast damping result.

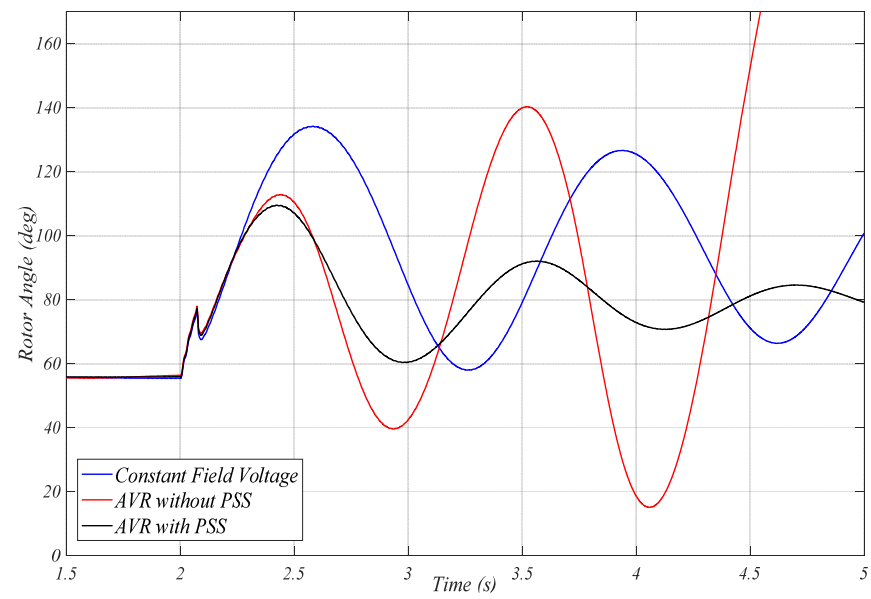

Figure 6. Generator rotor angle for SMIB system during 70ms fault

\section{SYSTEM MODEL}

The Single Machine Infinite Bus (SMIB) system considered in the research work has the parameters of the SMIB system used in [30]. The transmission system has been extended to include a parallel threeterminal thyristor converter configuration with a parallel AC line as shown in Figure 7. In other to evaluate the performance of this MTDC system on the generator transient stability, a $24 \mathrm{kV}, 2220$ MVA synchronous generator was modelled with alternator supplied exciter with $E f_{\max }$ and $E f_{\min }$ independent of the terminal voltage. The exciter was IEEE type AC4A exciter with IEEE PSS1A stabilizer for damping out oscillations during the system disturbance. Each converter's controller parameters rated, and actual power transfer and DC line specifications are shown in Table 2, while the generator ratings and AC lines specification are shown in the Table 3. The MTDC controller models used resemble that of the conventional point-to-point system which has been discussed in $[12,25,36]$ with modification made to the PI and the VDCOL control parameters to obtain a desired V-I characteristics of the converter. The rectifier converter is on current control mode while the inverters are capable of switching between voltage control mode or current control mode based on system condition. The $I N V_{-} 1$ substation with extinction angle $\gamma=\gamma_{0}$ controls and defines the voltage level of the entire network while all other substations in are current controlled mode. A central master controller was used for power-sharing and current balancer between all the converters, and the rectifier station rated moderately to cater for the power transfer to both inverters. 


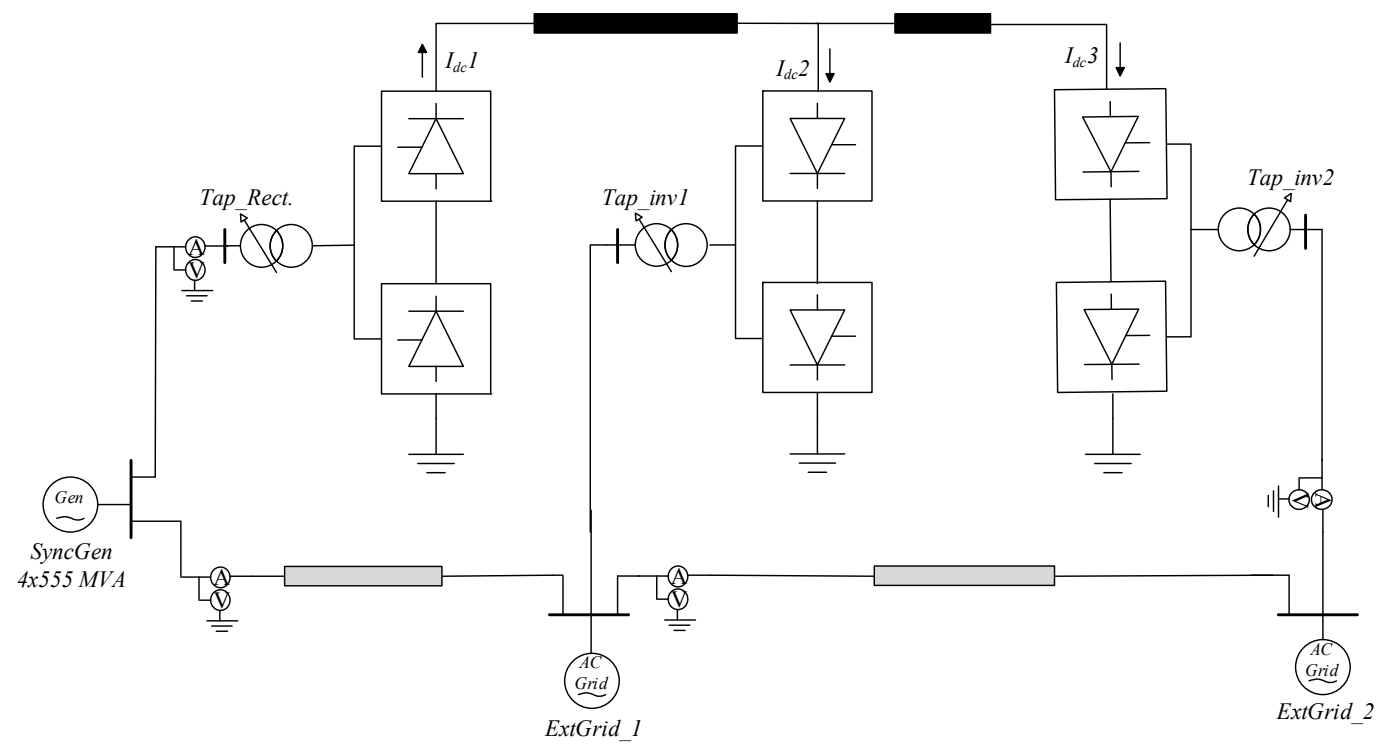

Figure 7. Parallel MTDC system embedded in AC Network model

Table 2. MTDC converter parameters

\begin{tabular}{|c|c|c|c|}
\hline & Rect. & Inv-1 & Inv-2 \\
\hline Rated/Actual power (MW) & $2000 / 1200$ & $1000 / 700$ & $1000 / 500$ \\
\hline Rated/Actual DC current (kA) & $4.0 / 2.4$ & $2.0 / 1.4$ & $2.0 / 1.0$ \\
\hline SCR & 2.5 & 3 & 2.5 \\
\hline AC voltage $(\mathrm{kV})$ & 450 & 450 & 500 \\
\hline \multirow[t]{2}{*}{$\gamma_{0}$ (inverter) } & & 15 & 15 \\
\hline & \multicolumn{3}{|c|}{ Transformer per 6 pulse thyristors } \\
\hline Rating (MVA) & 1200 & 700 & 600 \\
\hline Voltage $(\mathrm{kV})$ & $500 / 250$ & $500 / 250$ & $500 / 250$ \\
\hline \multirow[t]{2}{*}{ Leakage reactance $(\mathrm{pu})$} & 0.18 & 0.18 & 0.18 \\
\hline & \multicolumn{3}{|c|}{ PI Controller } \\
\hline Proportional Gain & 1.0989 & 1.5363 & 1.5363 \\
\hline Integral time constant (s) & 0.01092 & $\begin{array}{c}0.01524 \\
\text { VDCOL }\end{array}$ & 0.01524 \\
\hline Threshold input & $0.4-1.0$ & $0.4-0.9$ & $0.4-0.9$ \\
\hline \multirow[t]{3}{*}{ Threshold output } & $0.55-1.5$ & $0.55-1.0$ & $0.55-1.0$ \\
\hline & \multicolumn{3}{|c|}{ DC Transmission line (T-model) } \\
\hline & Line 1 & \multicolumn{2}{|c|}{ Line 2} \\
\hline $\mathrm{R}(\Omega)$ & 1.5 & \multicolumn{2}{|c|}{2.5} \\
\hline Reactor $(\mathrm{H})$ & 0.5968 & \multicolumn{2}{|c|}{0.5968} \\
\hline DC filter (uF) & 15 & \multicolumn{2}{|c|}{26} \\
\hline
\end{tabular}

Table 3. Generator and transmission line parameters

\begin{tabular}{|c|c|c|c|}
\hline \multicolumn{4}{|c|}{ Synchronous machine data } \\
\hline \multicolumn{2}{|c|}{ Genrator Data } & \multicolumn{2}{|c|}{ AVR and PSS } \\
\hline $\mathrm{Ra}(\mathrm{pu})$ & $0.003 \mathrm{pu}$ & Input signal & Speed \\
\hline $\mathrm{Xp}(\mathrm{pu})$ & $0.130 \mathrm{pu}$ & $\mathrm{T}_{\mathrm{R}}$ & $0.015 \mathrm{sec}$ \\
\hline $\mathrm{Xd}(\mathrm{pu})$ & $1.81 \mathrm{pu}$ & Vimax & $10 \mathrm{pu}$ \\
\hline $\mathrm{Xd}^{\prime}(\mathrm{pu})$ & $0.3 \mathrm{pu}$ & Vimin & $-10 \mathrm{pu}$ \\
\hline $\mathrm{Xd}^{\prime \prime}(\mathrm{pu})$ & $0.23 \mathrm{pu}$ & $\mathrm{K}_{\mathrm{A}}$ & $200 \mathrm{pu}$ \\
\hline $\mathrm{Td}_{\mathrm{o}}^{\prime}$ & $8.0 \mathrm{sec}$ & Efmax & $7.0 \mathrm{pu}$ \\
\hline $\mathrm{Td}_{0}{ }^{\prime \prime}$ & $0.0294(\mathrm{~s})$ & Efmin & $-6.4 \mathrm{pu}$ \\
\hline $\mathrm{Xq}$ & $1.76 \mathrm{pu}$ & $\mathrm{K}_{\mathrm{STAB}}$ & 9.5 \\
\hline $\mathrm{Xq}^{\prime}$ & $0.65 \mathrm{pu}$ & $\mathrm{T}_{\mathrm{W}}$ & $1.41 \mathrm{sec}$ \\
\hline $\mathrm{Xq}_{\mathrm{o}}{ }^{\prime \prime}$ & $0.25 \mathrm{pu}$ & $\mathrm{T}_{1}$ & $0.154 \mathrm{sec}$ \\
\hline $\mathrm{Tq}_{\mathrm{o}}^{\prime}$ & $1.0(\mathrm{~s})$ & $\mathrm{T}_{2}$ & $0.033 \mathrm{sec}$ \\
\hline $\mathrm{Tq}_{\mathrm{o}}{ }^{\prime \prime}$ & $0.07(\mathrm{~s})$ & $\mathrm{V}_{\text {stmax }}$ & 0.2 \\
\hline $\mathrm{H}$ & $3.5(\mathrm{~s})$ & $\mathrm{V}_{\text {stmin }}$ & -0.2 \\
\hline \multicolumn{4}{|c|}{ AC Transmission line (500kV base) } \\
\hline \multirow{2}{*}{\multicolumn{2}{|c|}{$\mathrm{R}(\mathrm{pu} / \mathrm{m})$}} & Line 1 & Line 2 \\
\hline & & 0.012 & 0.012 \\
\hline \multicolumn{2}{|c|}{$\mathrm{X}(\mathrm{pu} / \mathrm{m})$} & 0.12 & 0.12 \\
\hline \multicolumn{2}{|c|}{$\mathrm{B}(\mathrm{pu} / \mathrm{m})$} & 2.0 & 2.0 \\
\hline
\end{tabular}




\section{SIMULATION RESULTS}

To investigate the impact of MTDC system on power system rotor angle stability, a solid three-phase short circuits fault was applied at the RECT, INV_1, and INV_2 substations one after the other and the critical clearing time $T_{c}$ was recorded. The generator power output, rotor angle, generator speed, exciter field voltage, and the synchronizing torque are the major observation of this study. These parameters, including $P_{e}-\delta$ diagram, were depicted on a subplot to illustrate system performance before, during, and after the fault period. DC power, voltage and current were also illustrated on a plot to analyse the converter current contribution during and after the fault condition of the system.

After applying fault at simulation time $t=2 s$, it was found out that $I N V_{-} 1$ linking synchronous generator with $I N V \_2$ has the least critical clearing time $T_{c}=0.081 \mathrm{~s}$, while the generator bus and the INV_2 bus has a clearing time of $0.11 \mathrm{~s}$ and $0.18 \mathrm{~s}$ respectively. Solution time steps of $50 \mu \mathrm{s}$ and channel plot step of $500 \mu \mathrm{s}$ were used in computing the results.

Figure 8 shows the active and reactive power output from the synchronous generator. From this plot, a disturbance on the weakest $I N V_{-} 1$ bus resulted in a large drop in the active power generated from $1750 \mathrm{MW}$ to $280 \mathrm{MW}$, which result in the increase of the reactive power supplied to the system. The oscillations generated were quickly damped out with the help of the MTDC VDCOL controller which act as a fault minimizer. This shows the system is transiently stable.

The DC power, current and voltage are shown in Figure 9 to Figure 11. From Figure 9, the fault caused the VDCOL controller to reduce the current order to allow minimum power flow across the converter. As also seen in Figures 10 and 11, the current shoot above 5kA while the voltage dips down to $-200 \mathrm{kV}$, however, with VDCOL set point, the MTDC system only recorded a high current inflow due to the current contribution from the three converters but recorded no commutation failure at the two inverters.

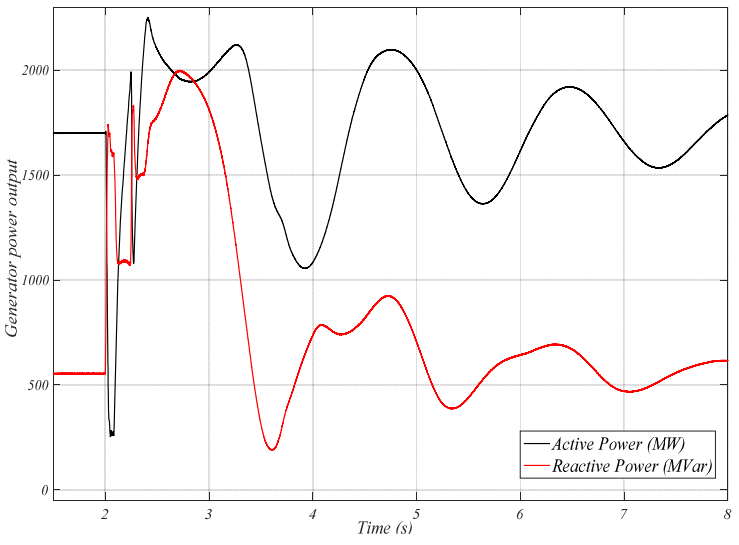

Figure 8. Synchronous generator power output

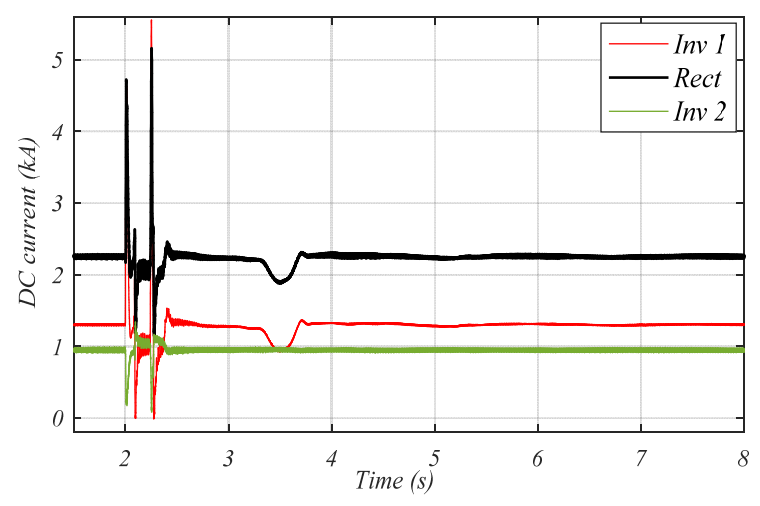

Figure 10. MTDC current

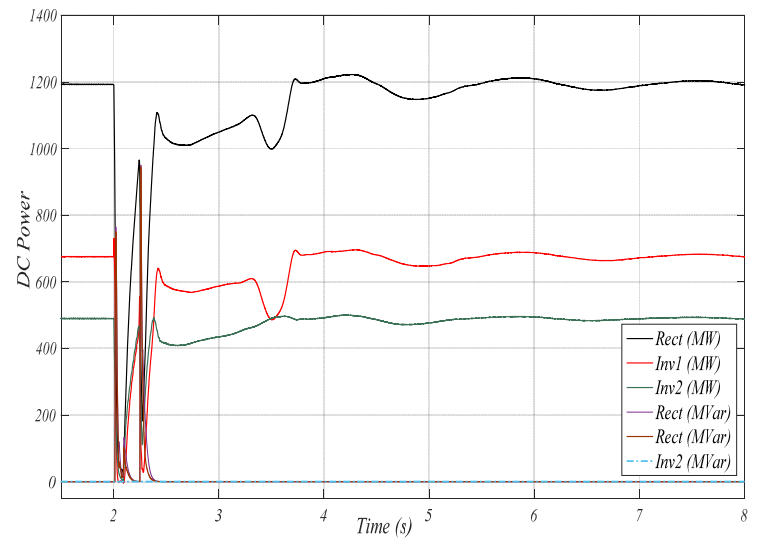

Figure 9. DC power across the three converters

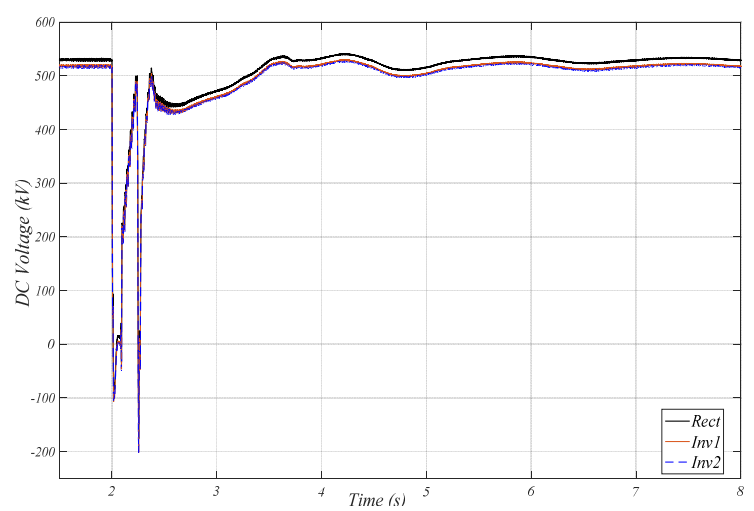

Figure 11. DC voltage for the three converters 
Rotor angle dynamics can be seen in Figure 12 following a three-phase short circuits fault on the $I N V_{-} l$ bus. A change of operating point was observed, causing the generator rotor angle $\delta$ to accelerate until it reached its maximum $\delta \max =175^{\circ}$, the point above which the systems become unstable. This can be in the second scenario where double AC transmission lines were used in replacement of the MTDC system. The generator having yielded its excitation control, and without supplementary controller support from the MTDC link, caused the synchronous machine to lose its stability at the first swing. The generator excitation voltage in Figure 13 also follows the same condition of a stable operating state during MTDC link interconnection. It, however, became unstable during the second scenario of double AC circuits replacement. This caused the synchronous machine to have yielded all its controlling capability leading to the field voltage swings between its VFmin and VFmax value of -6.4 and 7.0pu respectively. This was not so when MTDC link was in operation as the system maintained its stability with positive damping of oscillations.

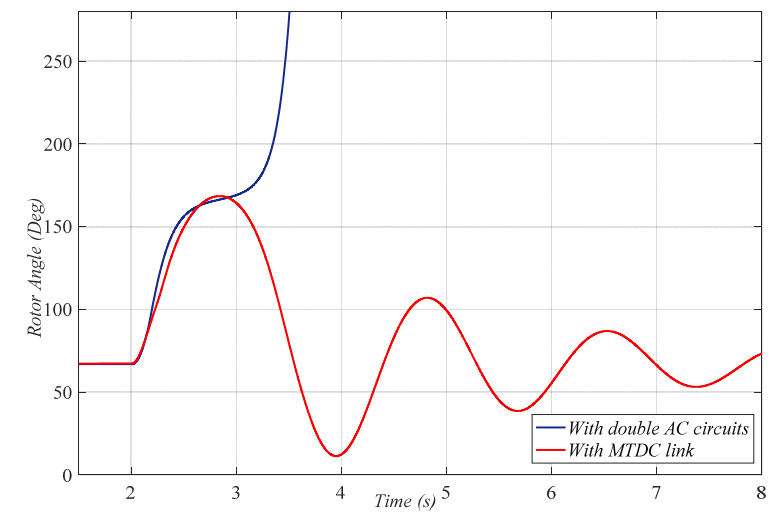

Figure 12. Synchronous generator rotor angle response (deg)

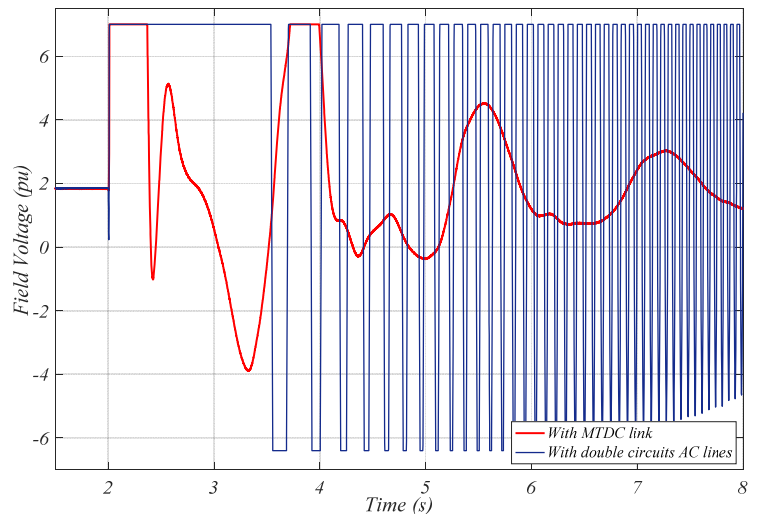

Figure 13. Synchronous generator exciter field voltage $(\mathrm{pu})$

The rotor angular speed in Figure 14 during MTDC link interconnection recorded an increase in frequency up to $380.8 \mathrm{rad} / \mathrm{s}$ thereafter dipping down to $373.5 \mathrm{rad} / \mathrm{s}$. These swings were quickly damped out from the second and subsequent oscillations of the rotor angle. The same generator angular speed experience the same disturbance with the second scenario of double AC transmission lines. This caused the generator speed to increase to $382.8 \mathrm{rad} / \mathrm{s}$ which further led to an unexpanded kinetic energy which results in a continuous increase of the rotor speed and angle $\left(P_{e}<P_{m}\right)$ and thus to loss of synchronism due to lack of decelerating torque to reduce the rotor speed.

Figure 15 and Figure 16 show the Pe $-\delta$ diagram for two case study of MTDC system and double AC transmission lines respectively. From Figure 15 , following a fault at $\mathrm{t}=2 \mathrm{~s}$, the active power was observed to dip to $280 \mathrm{MW}$ at $\delta=70^{\circ}$. When the fault was cleared at $\mathrm{t}=2.081 \mathrm{~s}$, a sharp increase of active power was observed, reaching a maximum value $P_{\text {emax }}=2300 \mathrm{MW}$, and $\delta_{\max }=175^{\circ}$. This plot also shows bounded post-fault oscillations, with the system returning to its pre-fault steady state condition. This shows that the pre-fault and post-fault bounded area $A_{1}$ and $A_{2}$ respectively are of equal or less accelerating power (i.e. $A_{1}-A_{2} \leq=0$ ). Figure 16 shows the second scenario of $500 \mathrm{kV}$ double circuits AC transmission lines used, instead of the MTDC link, in interconnecting the infinite busses to the synchronous generator. This plot shows a continuous increase of the rotor angle above $\delta_{\max }=175^{\circ}$ at first swing with the continuous oscillation of the active power $\left(P_{a c}\right)$ between $\pm 2000 \mathrm{MW}$. This oscillation tends to reduce in amplitude but at an exceedingly large rotor angle degree. This result from loss of synchronizing effect from both the AVR and PSS which causes the generator to lose synchronism with subsequent oscillations and the additional impedance added to the system which resulted in a more weakened grid strength leading to the cascading of the entire SMIB network.

Figure 17 shows the generator output voltage compared to its reference value. The generator used was set to a constant reference value of $1.01 \mathrm{pu}$. It can be observed that following the fault, the machine output voltage deviates from its reference value but is eventually settling to a steady state value. The synchronizing torque is shown in Figure 18. It can be observed that following the fault, the synchronizing torque experiences a dip during fault, but it then increases after a fault has been cleared and the electrical torque is eventually settling to a normalized reference value. 


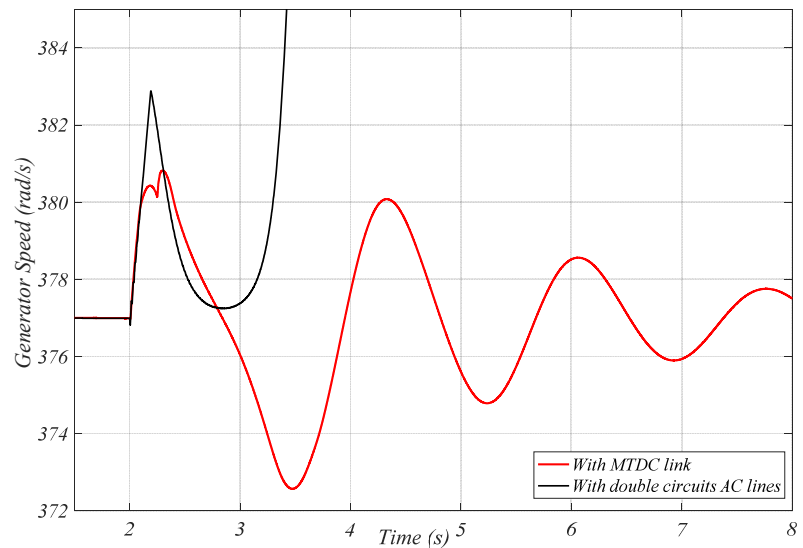

Figure 14. Synchronous generator speed $(\mathrm{rad} / \mathrm{s})$

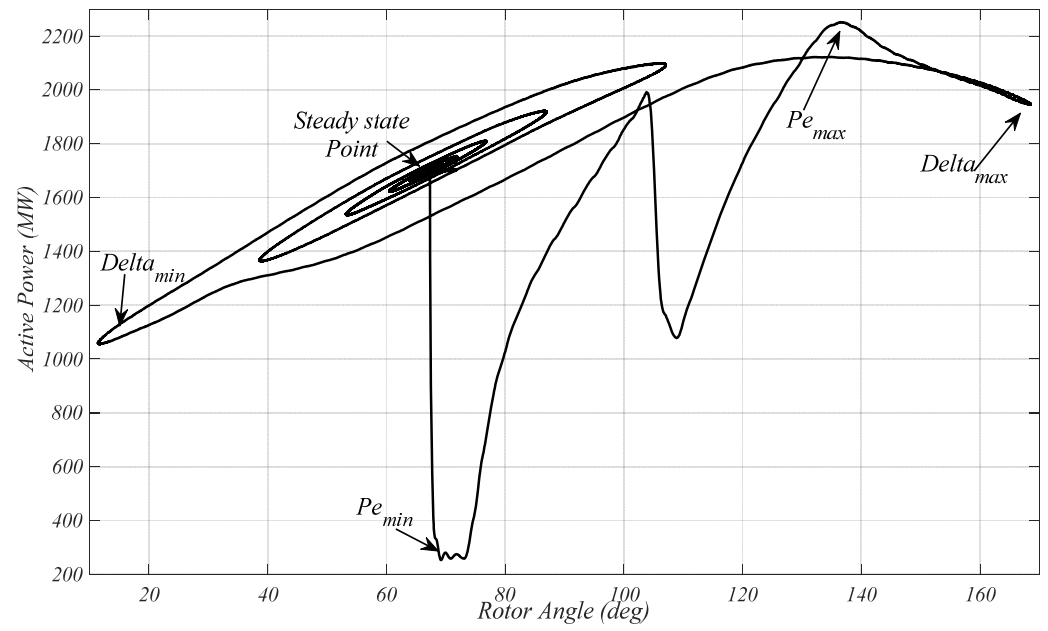

Figure 15. Generator Power - angle (Pe- $\delta$ ) diagram during stable condition

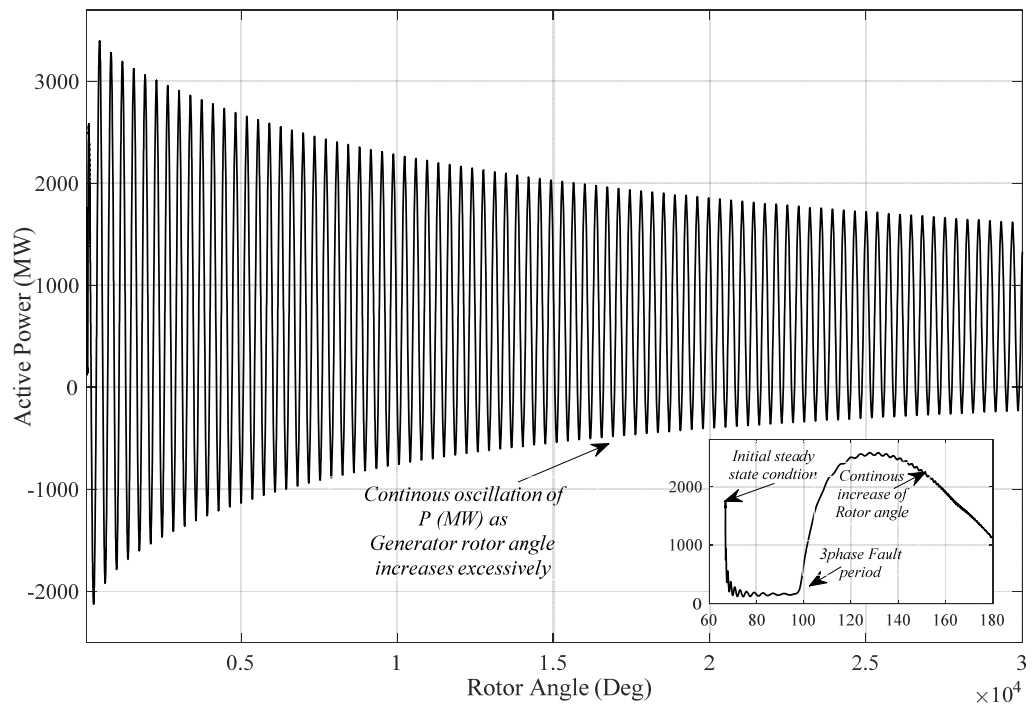

Figure 16. Generator power - angle (Pe- $\delta$ ) diagram during unstable condition while using $2 \times 500 \mathrm{kV}$ AC circuits (MTDC link out of service) 


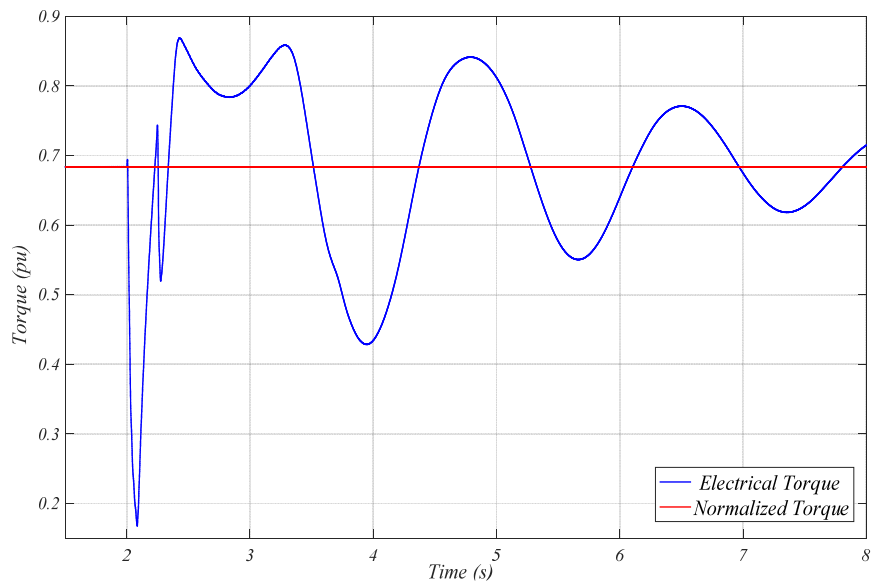

Figure 17. Generator output voltage

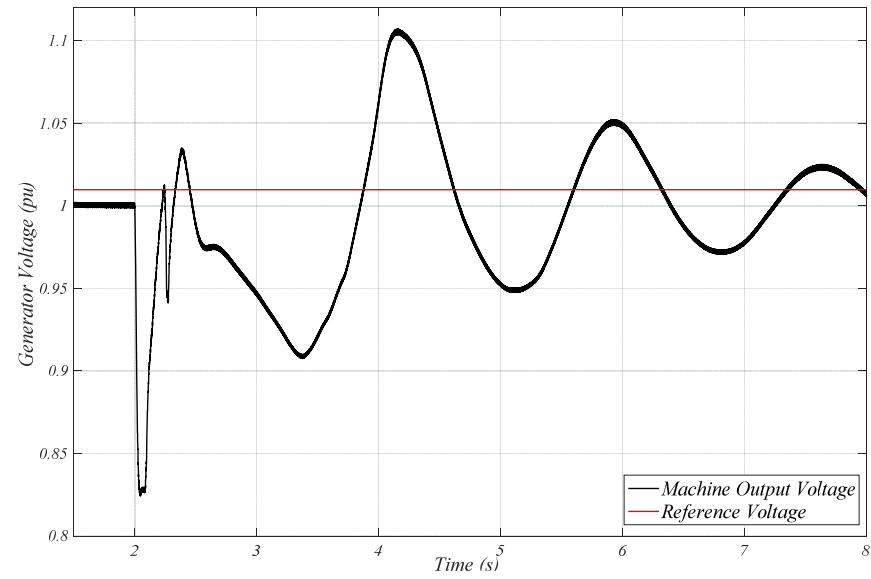

Figure 18. Synchronising torque

\section{CONCLUSION}

The performance evaluation of a three-terminal HVDC model on rotor angle stability of a weak SMIB transmission network has been investigated in this paper. In order to investigate the impact of this MTDC link on the transient stability of the study system, two case studies have been considered in this paper. A case study where the MTDC link was replaced with $500 \mathrm{kV}$ double circuits AC line was initially investigated. In this case study, the results showed a continuous power oscillation at increasing rotor angle degree during the three-phase short circuits fault at the $I N V-1$ station (linking the synchronous generator and the infinite bus). Subsequently, the second case study involved the placement of a three-terminal HVDC model in parallel with a single AC line into the SMIB network, and the same three-phase short circuits fault was applied at the AC side of $I N V_{-} I$ substation with the transmission system having the same operating points of power transfer in each line as in the previous study. The results have shown that this disturbance caused a transient increase in the DC current and a non-severe commutation failure at the converters station. Being a meshed network, with $I N V_{-} l$ substation linking both the synchronous generator bus and the $I N V_{-} 2$ substations, this fault led to an increase in generator rotor angle reaching $\delta=175^{\circ}$, and with the help $\overline{\mathrm{DC}}$ converter controller and fast response of the PSS, the system oscillations were quickly damped out. Thus, the results in this paper show that MTDC system incorporated into a weak AC network helped in improving the system operating condition and allows quick recovery of the system after an AC fault. Thus, utilizing MTDC lines compared to AC lines of same ratings will not only increase in power carrying capacity but will help in the reduction and quick damping of oscillations amplitude, and serves as AC reactive power support. The results in this paper thus give system planners more knowledge of the LCC-MTDC system in a weak $\mathrm{AC}$ grid, and its fault current contribution into such $\mathrm{AC}$ grid and the interconnecting synchronous generator. The power system stability margin can further be enhanced with proper utilisation of faster fault detection and isolation controllers. 


\section{ACKNOWLEDGEMENTS}

The author wishes to thank the Eskom Power Plant Engineering Institute Specialization Centre for HVDC and FACTS and Eskom TESP for their support.

\section{REFERENCES}

[1] G. Stein and T. M. Letcher, "Integration of PV Generated Electricity into National Grids," in A Comprehensive Guide to Solar Energy Systems, ed: Elsevier, pp. 321-332, 2018.

[2] K. Mbangula, O. Oni, and I. Davidson, "The Impact of HVDC Schemes on Network Transient Rotor Angle Stability," in 24th Southern African Universities Power Engineering Conference, South Africa January, 2016.

[3] S. Akkari, "Control of a multi-terminal HVDC (MTDC) system and study of the interactions between the MTDC and the AC grids," Université Paris-Saclay, 2016.

[4] O. E. Oni, I. E. Davidson, and K. N. Mbangula, "A review of LCC-HVDC and VSC-HVDC technologies and applications," in 2016 IEEE 16th International Conference on Environment and Electrical Engineering (EEEIC), pp. 1-7, 2016

[5] E. Kontos, R. T. Pinto, S. Rodrigues, and P. Bauer, "Impact of HVDC transmission system topology on multiterminal DC network faults," IEEE Transactions on Power Delivery, vol. 30, pp. 844-852, 2015.

[6] L. Tang and B.-T. Ooi, "Protection of VSC-multi-terminal HVDC against DC faults," in 2002 IEEE 33rd Annual IEEE Power Electronics Specialists Conference. Proceedings (Cat. No. 02CH37289), pp. 719-724, 2002.

[7] D. T. Oyedokun, K. A. Folly, and S. P. Chowdhury, "Effect of converter DC fault on the transient stability of a Multi-Machine Power System with HVDC transmission lines," in AFRICON, 2009. AFRICON '09., pp. 1-6, 2009.

[8] O. E. Oni, I. E. Davidson, and K. N. Mbangula, "Dynamic voltage stability studies using a modified IEEE 30-bus system," in 2016 IEEE 16th International Conference on Environment and Electrical Engineering (EEEIC), pp. 1-6, , 2016.

[9] O. E. Oni, I. E. Davidson, and K. N. Mbangula, "Voltage stability improvement of a multi-machine system using HVDC," in 2016 Clemson University Power Systems Conference (PSC), pp. 1-8, 2016.

[10] P. Rodriguez and K. Rouzbehi, "Multi-terminal DC grids: challenges and prospects," Journal of Modern Power Systems and Clean Energy, vol. 5, pp. 515-523, 2017.

[11] M. Hu, C. Fu, J. Wang, H. Rao, and H. Liu, "Real time digital simulation of the parallel multi-terminal HVDC transmission system," in 2012 IEEE International Conference on Power System Technology, pp. 1-5, 2012.

[12] M. Hegi, M. Bahrman, G. Scott, and G. Liss, "Control of the Quebec-New England Multiterminal HVDC System," in Cigre International Council on Large Electric systems, pp. 14-04, 1988.

[13] V. C. Collet Billon, J. P. Taisne, V. Arcidiacono, and F. Mazzoldi, "The Corsican tapping: from design to commissioning tests of the third terminal of the Sardinia-Corsica-Italy HVDC," IEEE Transactions on Power Delivery vol. 4, pp. 794-799, 1989.

[14] R. S. Thallam, "Review of the design and performance features of HVDC systems connected to low short circuit ratio AC systems," IEEE Transactions on Power Delivery, vol. 7, pp. 2065-2073, 1992.

[15] Y. Liu and Z. Chen, "Short Circuit Ratio analysis of multi-infeed HVDC system with a VSC-HVDC link," in IECON 2011 - 37th Annual Conference of the IEEE Industrial Electronics Society, pp. 949-954, 2011.

[16] H. Xiao, Y. Li, J. Zhu, and X. Duan., Efficient approach to quantify commutation failure immunity levels in multiinfeed HVDC systems. IET Generation, Transmission \&amp; Distribution, vol. 10(4), pp. 1032-1038, 2016, [Online], Available: https://digital-library.theiet.org/content/journals/10.1049/iet-gtd.2015.0800

[17] L. Yan and C. Zhe, "Transient voltage stability analysis and improvement of a network with different HVDC systems," in Power and Energy Society General Meeting, 2011 IEEE, pp. 1-8, 2011.

[18] J. Renedo, A. Garc1'a-Cerrada, and L. Rouco, "Active Power Control Strategies for Transient Stability Enhancement of AC/DC Grids With VSC-HVDC Multi-Terminal Systems," IEEE Transactions on Power Systems, vol. 31, pp. 4595-4604, 2016.

[19] C. D. Vournas, P. W. Sauer, and M. A. Pai, "Relationships between voltage and angle stability of power systems," International Journal of Electrical Power \& Energy Systems, vol. 18, pp. 493-500, 1996.

[20] J. Song, "Power System Stability: Modelling, Analysis and Control [Bookshelf]," IEEE Control Systems Magazine, vol. 37, pp. 99-100, 2017.

[21] S. R. Salkuti, "Transient Stability Enhancement using Thyristor Controlled Ceries Compensator," International Journal of Electrical and Computer Engineering (IJECE), vol. 9, pp. 884-893, 2019.

[22] L. Cong, Y. Wang, and D. Hill, "Transient stability and voltage regulation enhancement via coordinated control of generator excitation and SVC," International Journal of Electrical Power \& Energy Systems, vol. 27, pp. 121-130, 2005.

[23] G. Kenné, R. Goma, H. Nkwawo, F. Lamnabhi-Lagarrigue, A. Arzandé, and J. C. Vannier, "An improved direct feedback linearization technique for transient stability enhancement and voltage regulation of power generators," International Journal of Electrical Power \& Energy Systems, vol. 32, pp. 809-816, 2010.

[24] K. Mbangula, I. Davidson, and R. Tiako, "Improving power system stability of South Africa's HVAC network using strategic placement of HVDC links," CIGRE Science \& Engineering Journal (CSE), vol. 5, pp. 71-78, 2016.

[25] R. Jotten, J. P. Bowles, G. Liss, C. J. B. Martin, and E. Rumpf, "Control in HVDC Systems: The state of the art. Part II : Multiterminal Systems," in Cigre International Conference on Large High Voltage Electric Systems, Paris, 1980.

[26] J. Hongbo and A. Ekstrom, "Multiterminal HVDC systems in urban areas of large cities," IEEE Transactions on Power Delivery, vol. 13, pp. 1278-1284, 1998. 
[27] R. L. Vasquez-Arnez, J. A. Jardini, and M. T. Bassini, "Dynamic Performance of Line Commutated ConverterBased Multiterminal HVDC Systems," Przeglad Elektrotechniczny, vol. 91, pp. 247-253, 2015.

[28] M. Eremia, C.-C. Liu, and A.-A. Edris, Advanced solutions in power systems: HVDC, FACTS, and Artificial Intelligence, vol. 52, John Wiley \& Sons, 2016.

[29] J. Tu, Y. Pan, J. Zhang, B. Zeng, J. Jia, and J. Yi, "Transient reactive power characteristics of HVDC during commutation failure and impact of HVDC control parameters," The Journal of Engineering, vol. 2017, pp. 1134-1139, 2017.

[30] P. Kundur, N. J. Balu and M. G. Lauby, Power System Stability and Control, vol. 7. New York, McGraw-Hill, 1994.

[31] C. J. Mozina, M. Reichard, Z. Bukhala, S. Conrad, T. Crawley, J. Gardell, et al., "Coordination of generator protection with generator excitation control and generator capability," in 54th Annual Conference on Record of Pulp and Paper Industry Technical Conference, pp. 62-76, 2008.

[32] A. Murdoch, G. Boukarim, B. Gott, M. D'antonio, and R. Lawson, "Generator over excitation capability and excitation system limiters," in IEEE Power Engineering Society Winter Meeting, pp. 215-220, 2001.

[33] M. Pavella, D. Ernst, and D. Ruiz-Vega, Transient stability of power systems : a unified approach to assessment and control: Springer US, 2019.

[34] L. L. Grigsby, Power System Stability and Control, Third Edition: Taylor \& Francis, 2012.

[35] Y. Dong and H. R. Pota., "Transient stability margin prediction using equal-area criterion," IEE Proceedings C (Generation, Transmission and Distribution), vol. 140(2), pp. 96-104, 1993.

[36] M. Szechtman, T. Wess, and C. Thio, "A benchmark model for HVDC system studies," in International Conference on AC and DC Power Transmission, pp. 374-378, 1991. 